in vivo $35: 3125-3135(2021)$

doi:10.21873/invivo.12607

\title{
Suppression of Tumor Growth in a Rabbit Hepatic Cancer Model by Boron Neutron Capture Therapy With Liposomal Boron Delivery Systems
}

\author{
HIRONOBU YANAGIE ${ }^{1,2,3}$, MASASHI YANAGAWA ${ }^{4}$, YASUYUKI MORISHITA $^{5}$, ATSUKO SHINOHARA $^{6}$, \\ NOVRIANA DEWI ${ }^{7}$, YASUMASA NONAKA $^{8}$, YOSHITAKA FURUYA $^{9}$, RYOUJI MIZUMACHI $^{10}$, \\ YUUJI MURATA ${ }^{10}$, HIROYUKI NAKAMURA ${ }^{11}$, MINORU SUZUKI ${ }^{12}$, YOSHINORI SAKURAI ${ }^{12}$, HIROKI TANAKA ${ }^{12}$, \\ SHINICHIRO MASUNAGA ${ }^{12}$, KOJI ONO ${ }^{13}$, TAKUMICHI SUGIHARA ${ }^{7}$, MASAYUKI NASHIMOTO ${ }^{3}$, \\ HARUO YAMAUCHI ${ }^{2,14}$, MINORU ONO ${ }^{2,14}$, JUN NAKAJIMA ${ }^{2,15}$ and HIROYUKI TAKAHASHI ${ }^{1,2}$ \\ ${ }^{1}$ Institute of Engineering Innovation, School of Engineering, The University of Tokyo, Tokyo, Japan; \\ ${ }^{2}$ Cooperative Unit of Medicine and Engineering, The University of Tokyo Hospital, Tokyo, Japan; \\ ${ }^{3}$ Research Institute of Healthy Living, Niigata University of Pharmacy and Applied Life Sciences, Niigata, Japan; \\ ${ }^{4}$ Veterinary Medical Center, Obihiro University of Agriculture and Veterinary Medicine, Obihiro, Japan; \\ ${ }^{5}$ Department of Human and Molecular Pathology, \\ Graduate School of Medicine, The University of Tokyo, Tokyo, Japan; \\ ${ }^{6}$ Graduate School of Humanities, Seisen University, Tokyo, Japan; \\ ${ }^{7}$ Laboratory of Pharmaceutical Chemistry, Faculty of Pharmaceutical Sciences, \\ Niigata University of Pharmacy and Applied Life Sciences, Niigata, Japan; \\ ${ }^{8}$ Department of Surgery, Keiai-kai Houyou Hospital, Hanamaki, Japan; \\ ${ }^{9}$ Department of Surgery, Sodegaura Satukidai Hospital, Sodegaura, Japan; \\ ${ }^{10}$ Department of Pharmacology, Kumamoto Institute Branch, LSI Medience Ltd. Co., Uto, Japan; \\ ${ }^{11}$ Laboratory for Chemistry and Life Science, Institute of Innovative Research, \\ Tokyo Institute of Technology, Yokohama, Japan; \\ ${ }^{12}$ Institute for Integrated Radiation and Nuclear Science, Kyoto University, Osaka, Japan; \\ ${ }^{13}$ BNCT Joint Clinical Institute, Osaka Medical Pharmaceutical University, Osaka, Japan; \\ ${ }^{14}$ Department of Cardiovascular Surgery, The University of Tokyo Hospital, Tokyo, Japan; \\ ${ }^{15}$ Department of Thoracic Surgery, The University of Tokyo Hospital, Tokyo, Japan
}

\begin{abstract}
Background/Aim: Tumor cell destruction by boron neutron capture therapy (BNCT) is attributed to the nuclear reaction between ${ }^{10} \mathrm{~B}$ and thermal neutrons. The accumulation of ${ }^{10} B$ atoms in tumor cells without affecting adjacent healthy cells is crucial for effective BNCT. We previously reported that several types of liposomal boron
\end{abstract}

This article is freely accessible online.

Correspondence to: Hironobu Yanagie, MD, Ph.D., Institute of Engineering Innovation, School of Engineering, The University of Tokyo, 2-11-16 Yayoi, Bunkyo-ku, Tokyo 113-8656, Japan. Tel: +81 358009194, Fax: +81 358009195, e-mail: h.yanagie@ gmail.com

Key Words: Boron neutron capture therapy, BNCT, transferrinconjugated polyethylene glycol, $\mathrm{PEG}$, liposome, ${ }^{10} \mathrm{~B}$-boronododecaborate ${ }^{10} \mathrm{BSH}$, distearoylboron lipid, DSBL, hepatocellular carcinoma, HCC delivery systems (BDS) delivered effective numbers of boron atoms to cancer tissues, and showed tumor-growth suppression after thermal neutron irradiation. In the present study, we examined the effects of BNCT after intra-arterial infusion of ${ }^{10} \mathrm{~B}$-borono-dodecaborate $\left({ }^{10} \mathrm{BSH}\right)$ by liposomal $B D S$ in rabbit hepatic cancer models. Materials and Methods: We prepared ${ }^{10}$ BSH-entrapped transferrinconjugated polyethylene glycol liposomes constructed with distearoyl-boron lipid (TF-PEG-DSBL), and performed thermal neutron irradiation at the Kyoto University Institute for Integrated Radiation and Nuclear Science after intraarterial infusion into rabbit VX-2 hepatic tumors. Results: Concentrations of ${ }^{10} B$ in VX-2 tumors on delivery with TF$P E G$-DSBL liposomes reached 25 ppm on day 3 after the injection. Tumor growth was suppressed by thermal neutron irradiation after intra-arterial injection of this ${ }^{10} \mathrm{BSH}$ containing liposomal BDS, without damage to normal cells. Conclusion: The present results demonstrate the applicability 
of ${ }^{10} B$-containing TF-PEG-DSBL liposomes as a novel intraarterial boron carrier in BNCT for cancer.

Hepatocellular carcinoma (HCC) is one of the most difficult types of tumor to cure by surgery, chemotherapy, or radiotherapy $(1,2)$. Surgery is only indicated for $30 \%$ of patients with HCC due to the complications of liver cirrhosis and multiple intrahepatic tumors. In clinical settings, anticancer agents are generally administered intra-arterially after mixing with iodized poppy-seed oil (3). However, since anticancer agents easily separate from iodized poppy-seed oil within a short time period, they do not effectively accumulate in tumor cells. Higashi and co-workers previously reported the preparation of a long-term inseparable water-in-oil-in-water (WOW) emulsion containing 8-60 mg of epirubicin for use in arterial injection therapy for patients with $\mathrm{HCC}$, and showed reductions in tumor sizes in patients with HCC (4-6).

Nanoscale liposomes have been extensively investigated as carriers for anticancer drugs in attempts to direct active agents to tumors or protect sensitive tissues from toxicity. Since the size of the WOW emulsion is in the micron $(\mu \mathrm{m})$ scale, liposomes are able to deliver drugs to cancer cells in tumors via the enhanced permeability and retention effect.

Boron neutron capture therapy (BNCT) has been used to inhibit the growth of various cancer types, such as malignant brain tumors, melanoma, and head and neck tumors (7-9). The cytotoxic effects of BNCT are due to a nuclear reaction between ${ }^{10} \mathrm{~B}$ and thermal neutrons, which induces high linear-energy transfer of $\alpha$ particles and lithium recoil. These particles ( $\alpha$ and ${ }^{7} \mathrm{Li}$ ) destroy cells within an approximately $10-\mu \mathrm{m}$ path length from the site of the capture reaction. Therefore, the development of selective boron delivery systems for effective BNCT is of importance (10-15). As one of these drug delivery systems, we reported that immunoliposomes carrying ${ }^{10} \mathrm{~B}$-boronododecaborate $\left({ }^{10} \mathrm{BSH}\right)$ exerted cytotoxic effects against human pancreatic carcinoma cells in vitro by BNCT (16), and an intratumoral injection of boronated immunoliposomes suppressed tumor growth in vivo by BNCT (17). We also previously prepared polyethylene glycol (PEG) liposomes as an effective ${ }^{10} \mathrm{~B}$ carrier $(18,19)$.

The accumulation of ${ }^{10} \mathrm{~B}$ atoms in tumor cells without affecting adjacent healthy cells is crucial for effective BNCT. Transferrin (TF)-conjugated PEG liposomes may be useful for in vivo cytoplasmic targeting by chemotherapeutic agents or plasmid DNAs that target cells. TF-PEG liposomes readily bind to cancer cells and are internalized by receptormediated endocytosis, which enhances the extravasation of liposomes into solid tumor tissue $(19,20)$.

We are interested in applying BNCT to the treatment of $\mathrm{HCC}$. Therefore, in the present study, we developed ${ }^{10} \mathrm{BSH}-$ entrapped TF-PEG liposomes with ${ }^{10} \mathrm{~B}$-distearoyl-boron lipid (DSBL) $(21,22)$. These liposomes were used as a selective boron delivery system to cancer tissues in a VX-2 hepatic tumor model in order to investigate the application of BNCT to the treatment of HCC with the aim of increasing the selection of therapies available for patients (Figure 1).

\section{Materials and Methods}

Preparation of PEG and TF-PEG liposomes containing ${ }^{10} \mathrm{~B}$ compound. Boron-entrapped liposomes were prepared by the reverse-phase evaporation method and extrusion method $(18,19)$.

The composition ratio of liposomes in uniting-type 25\% DSBL stealth liposomes (PEG-DSBL) was as follows: distearoylphosphatidylcholine (DSPC):DSBL:cholesterol:PEG-2000=0.75:0.25:1.0: 0.11 (mol ratio). The concentration of boron entrapped in PEGDSBL liposomes was 2, $700 \mathrm{ppm}$.

The composition element ratio of entrapping-type ${ }^{10} \mathrm{BSH}$-entrapped stealth (PEG) liposomes was as follows: DSPC: cholesterol:PEG$2000=1.0: 1.0: 0.11$ (mol ratio $)+{ }^{10} \mathrm{BSH}(125 \mathrm{mmol} / \mathrm{l})$. The enclosed boron concentration entrapped in PEG liposomes was 4700 ppm.

${ }^{10} \mathrm{BSH}$-entrapped TF-PEG-DSBL liposomes were prepared by the coupling of TF to the PEG-COOH moieties of PEG-DSBL liposomes according to the protocol described by Ishida et al. [DSPC:DSBL:cholesterol:PEG-2000=2840:336:1546:928 (/mg)] (20) (Figure 2).

Boron concentrations in prepared liposomes were measured using inductively coupled plasma atomic emission spectroscopy (ICPAES) (24).

Target tumor cells and rabbits. Rabbit VX-2 cells (a Shope virusderived squamous cell carcinoma cell line) were cultured in vitro and supplemented with $10 \%$ fetal bovine serum and $500 \mu \mathrm{g}$ streptomycin/penicillin under $5 \% \mathrm{CO}_{2}$ conditions. Female New Zealand white rabbits with VX-2 cells inoculated into the left lobe of the liver were obtained from Nihon SLC Ltd. (Shizuoka, Japan) and used at a mean body weight of $2 \mathrm{~kg}$ (23). The procedures for tumor implantation and animal sacrifice were in accordance with the approved guidelines of the Institution's Animal Ethics Committee and with the Declaration of Helsinki (approval number; LSI Medience: P090818 \& P100455, KUR: 2010-18 \& 25).

Evaluation of tumor-growth suppression by experimental BNCT. Rabbit VX-2 cells were inoculated into the left lobe of the liver, and 2 weeks after tumor cell inoculation, ${ }^{10} \mathrm{BSH}-\mathrm{TF}-\mathrm{PEG}-\mathrm{DSBL}$ liposomes were administered by an intra-arterial injection via the proper hepatic artery into the VX-2 rabbit hepatic tumor model. Tumor-bearing rabbits were irradiated with thermal neutrons (fluence: $2 \times 10^{12} \mathrm{n} / \mathrm{cm}^{-2}$ ) at the Kyoto University Institute for Integrated Radiation and Nuclear Science $48 \mathrm{~h}$ after the intra-arterial injection of liposomes. Neutron fluence was measured by gold foil at two points on the frontal side of the abdomen and rear side of the rabbit holder, while the gamma ray dose was assessed using a thermoluminescent dosimeter at the same points. After irradiation, the size of the tumor and the status of the abdomen were investigated on day 14 after BNCT by sacrificing rabbits for morphological observations. Pathological analyses were also performed on tumor samples resected after neutron irradiation, fixed in Optimal Cutting Temperature compound, and frozen at $-80^{\circ} \mathrm{C}$. Harvested tumor samples were sliced into 6 - $\mu$ m-thick sections using a cryostat and deposited on glass slides before being stained with hematoxylin and eosin. 


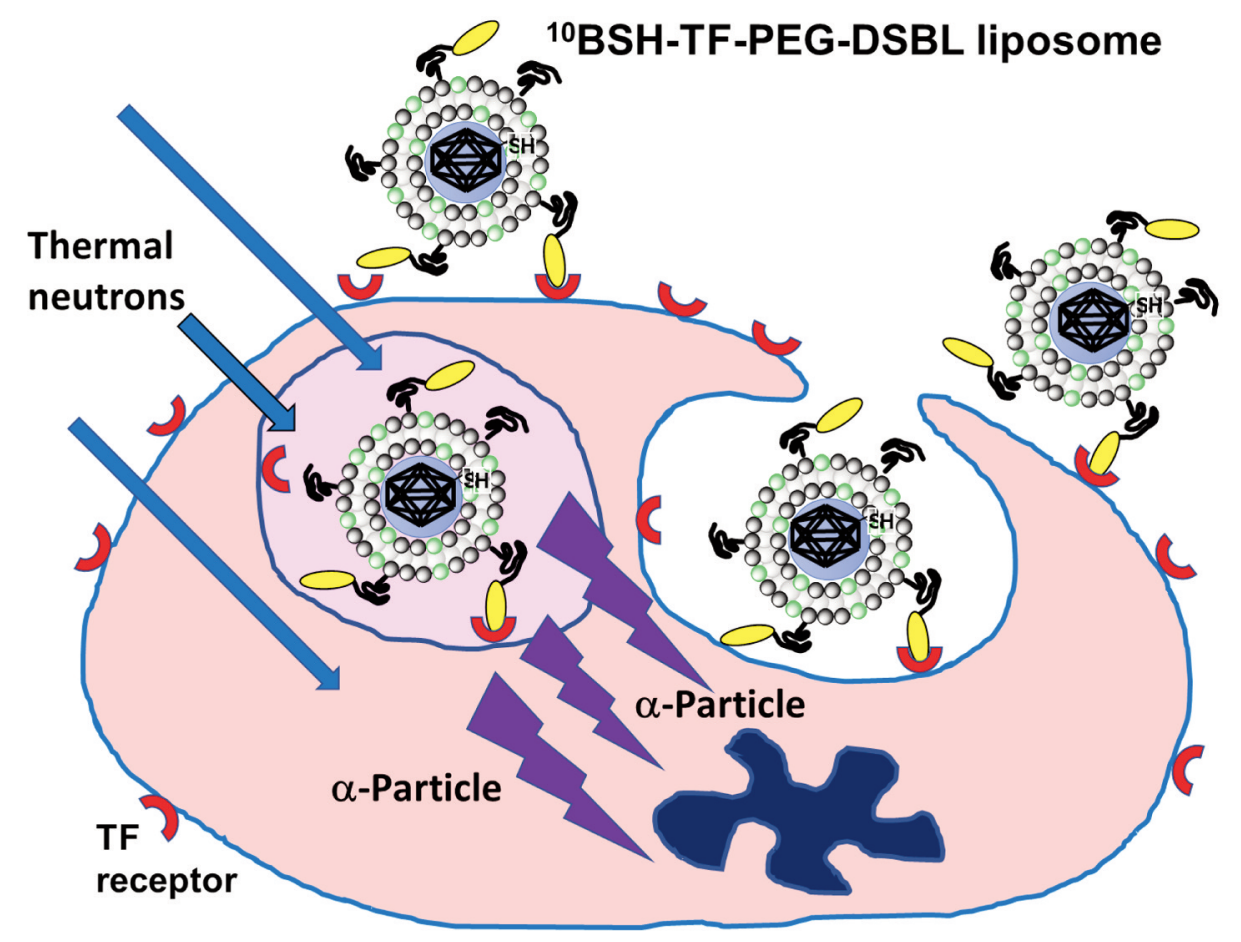

Figure 1. We propose the application of ${ }^{10} B$-borono-dodecaborate-entrapped transferrin-conjugated polyethyleneglycol-distearoylboron lipid-coated $\left({ }^{10} B S H-T F-P E G-D S B L\right)$ liposomes as a delivery carrier of boron compounds for intra-arterial injection in boron neutron capture therapy: As TF$P E G$ has an endocytic role, it can deliver ${ }^{10} B$ atoms into cancer cells. Use of DSBL increases the ${ }^{10} B$ concentration in cancer cells.
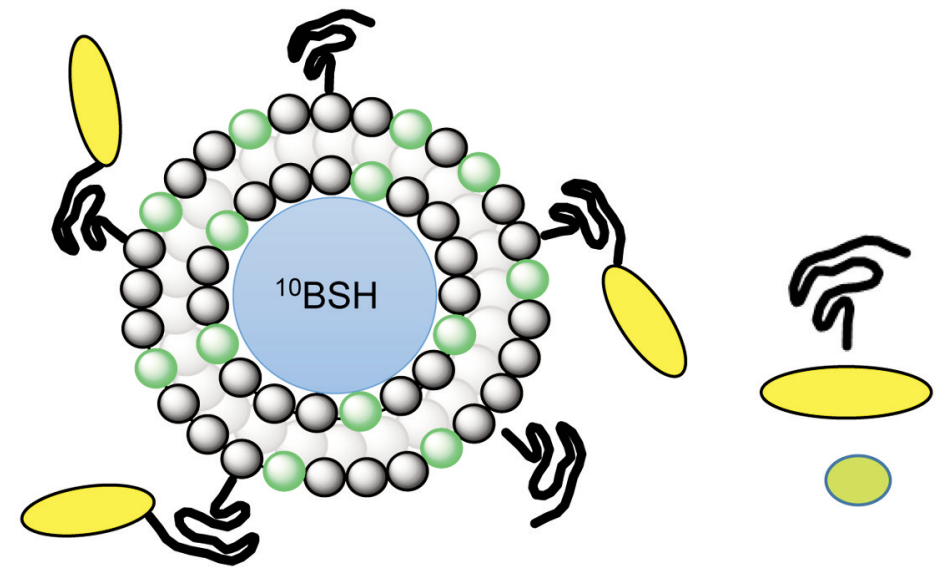

PEG

Transferrin

DSBL

Figure 2. Schema of ${ }^{10}$ B-borono-dodecaborate $\left({ }^{10} B S H\right)$-entrapped transferrin-conjugated polyethyleneglycol (PEG)-distearoylboron lipid (DSBL)coated liposomes.

Pathological findings of tumors after intra-arterial injection of ${ }^{10}$ BSH-PEG-DSBL liposomes. Histological and electron microscopic observations were performed. Rabbits were sacrificed 24 and $48 \mathrm{~h}$ after the injection of ${ }^{10} \mathrm{BSH}-\mathrm{PEG}-\mathrm{DSBL}$ liposomes. Livers were resected and stored in Optimal Cutting Temperature compound frozen at $-80^{\circ} \mathrm{C}$. Six-micrometer-thick sections of the same specimens were stained with hematoxylin and eosin for light microscopy to assess the induction of necrosis, hyalinization by BNCT. 


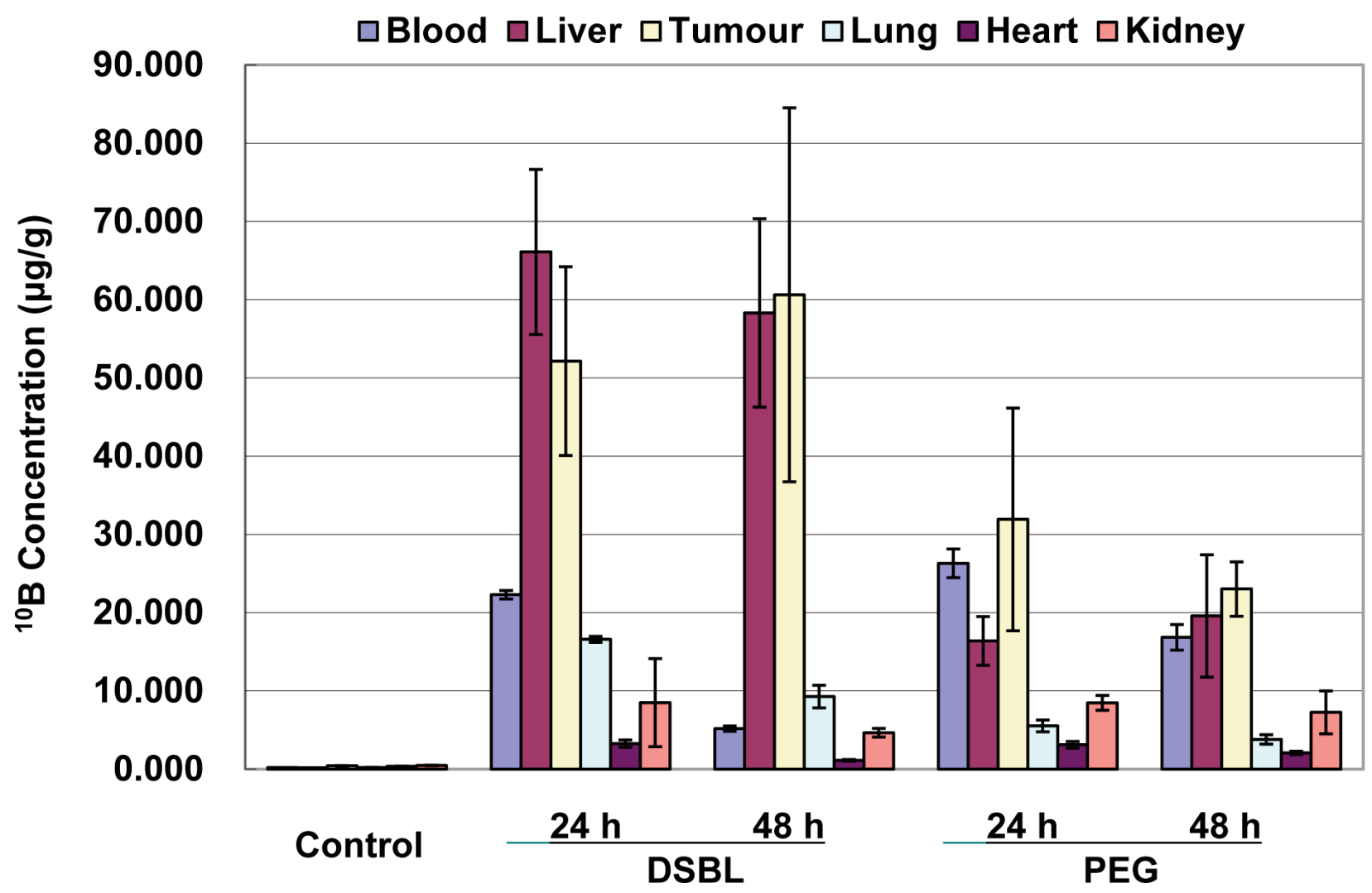

Figure 3. Measurement of boron concentrations in tumors and each organ after the intra-arterial injection of boron-entrapped polyethyleneglycol (PEG) liposomes in the VX-2 hepatic cancer-bearing rabbit model. Two types of ${ }^{10} \mathrm{~B}$-borono-dodecaborate $\left({ }^{10} B S H\right)$-PEG liposomes were prepared: Distearoylboron lipid (DSBL) type and simple entrapping PEG type. Concentrations of ${ }^{10} B$ were measured by inductively coupled plasma atomic emission spectroscopy at Juntendo University. Mean values and standard deviations were calculated $(n=3)$.

Measurement of ${ }^{10} \mathrm{~B}$ accumulated in each organ in vivo. We administered ${ }^{10} \mathrm{BSH}$-containing liposomes $(15 \mathrm{mg} / \mathrm{kg})$ to tumorbearing rabbits. Regarding the hepatic artery injection technique, the abdomen was opened under general anesthesia, the proper hepatic artery facing the liver was identified, the catheter or injection needle was inserted, and the hepatic artery injection of ${ }^{10} \mathrm{BSH}$ liposomes was performed. The administered volumes were $5.6 \mathrm{ml}$ for ${ }^{10} \mathrm{BSH}-\mathrm{PEG}-\mathrm{DSBL}$ liposomes and $3.3 \mathrm{ml}$ for ${ }^{10} \mathrm{BSH}-$ PEG liposomes. Boron concentrations in blood, VX-2 liver tumors, normal liver tissues, and other organs were measured using ICP-AES at 24 or $48 \mathrm{~h}$ after the intra-hepatic arterial injection of ${ }^{10} \mathrm{BSH}-\mathrm{PEG}-\mathrm{DSBL}$ or ${ }^{10} \mathrm{BSH}-\mathrm{PEG}$ loposomes under general anesthesia in the VX-2 rabbit liver tumor model. Mean values and standard deviations were calculated. The number of rabbits in each group was three.

We also measured ${ }^{10} \mathrm{~B}$ concentrations in blood, VX-2 liver tumors, and normal liver tissues using ICP-AES 24, 48, 72, or 120 $\mathrm{h}$ after the intra-hepatic arterial injection of ${ }^{10} \mathrm{BSH}-\mathrm{TF}-\mathrm{PEG}-\mathrm{DSBL}$ liposomes. Tissues were weighed immediately after dissection and recorded as wet weights. Results were expressed as $\mu \mathrm{g}{ }^{10} \mathrm{~B}$ per $\mathrm{g}$ tissue. Mean values and standard deviations were calculated.

\section{Results}

Characterization of liposomes. Mean ${ }^{10} \mathrm{~B}$ concentrations in liposomes were measured using ICP-AES. The concentration of ${ }^{10} \mathrm{~B}$ entrapped in ${ }^{10} \mathrm{BSH}-\mathrm{PEG}-\mathrm{DSBL}$ liposomes was 2700 $\mathrm{ppm}$, and that in ${ }^{10} \mathrm{BSH}-\mathrm{PEG}$ liposomes was $4,700 \mathrm{ppm}$. The ${ }^{10} \mathrm{~B}$ concentration entrapped in ${ }^{10} \mathrm{BSH}-\mathrm{TF}-\mathrm{PEG}-\mathrm{DSBL}$ liposomes was 3,200 ppm.

Comparison of ${ }^{10} B$ accumulation in each organ and biodistribution of ${ }^{10} \mathrm{BSH}-\mathrm{PEG}$ and ${ }^{10} \mathrm{BSH}-\mathrm{PEG}-\mathrm{DSBL}$ liposomes after intra-hepatic arterial injection. The ${ }^{10} \mathrm{~B}$ concentrations in the VX-2 tumor using ${ }^{10} \mathrm{BSH}-\mathrm{PEG}-\mathrm{DSBL}$ and ${ }^{10} \mathrm{BSH}-\mathrm{PEG}$ liposomes were $52.14 \pm 12.07$ and $31.92 \pm 14.23$ $\mu \mathrm{g} / \mathrm{g}$, respectively, $24 \mathrm{~h}$ after the intra-arterial injection, and were $60.62 \pm 23.89$ and $23.02 \pm 3.47 \mu \mathrm{g} / \mathrm{g}$, respectively, $48 \mathrm{~h}$ after (Figure 3 ). The ${ }^{10} \mathrm{~B}$ concentration in the tumor using DSBL liposomes was two-fold higher than that of ${ }^{10} \mathrm{BSH}-\mathrm{PEG}$ 
liposomes. The amount of boron that accumulated was also two-fold higher in hepatic tumors than in normal hepatic tissue (31 ppm on average) with ${ }^{10} \mathrm{BSH}-\mathrm{PEG}$ liposomes at $24 \mathrm{~h}$ after the intra-arterial injection (Figure 3).

Histological and electron microscopic findings of tumors after intra-arterial injection of ${ }^{10} \mathrm{BSH}-\mathrm{PEG}-\mathrm{DSBL}$ liposomes. Pathological findings revealed no damage to normal hepatic tissue with this dosage injection of ${ }^{10} \mathrm{BSH}-\mathrm{PEG}-\mathrm{DSBL}$ liposomes (Figure 4).

Hepatic biodistribution of ${ }^{10} B S H-T F-P E G-D S B L$ liposomes after intra-hepatic arterial injection. Modifications to the surface of PEG liposomes by conjugation with TF increased the ${ }^{10} \mathrm{~B}$ concentration in tumors to around $25 \mu \mathrm{g} / \mathrm{g}$ at $72 \mathrm{~h}$ after the intra-hepatic arterial injection of ${ }^{10} \mathrm{BSH}-\mathrm{TF}-\mathrm{PEG}-\mathrm{DSBL}$ liposomes into the VX-2 rabbit hepatic tumor model. The concentration of boron in normal hepatic tissue was 10-15 $\mu \mathrm{g} / \mathrm{g} 72 \mathrm{~h}$ after the intra-hepatic arterial injection (Figure 5). The tumor/normal liver ${ }^{10} \mathrm{~B}$ concentration ratio was at least 1.5 -fold higher until $120 \mathrm{~h}$ after intra-hepatic arterial injection (Figure 5). When ${ }^{10} \mathrm{BSH}-\mathrm{TF}-\mathrm{PEG}-\mathrm{DSBL}$ liposomes were administered intra-arterially at a dose of $6.4 \mathrm{mg}{ }^{10} \mathrm{~B} / \mathrm{kg}$, we observed the selective uptake of ${ }^{10} \mathrm{~B}$ by cancer tissues compared with that by normal hepatocytes in the VX-2 rabbit hepatic cancer model. TF-PEG-liposomes maintained a high ${ }^{10} \mathrm{~B}$ concentration in tumors, with concentrations higher than $25 \mu \mathrm{g} / \mathrm{g}$ for at least $72 \mathrm{~h}$ after intra-arterial injection. This high retention of ${ }^{10} \mathrm{~B}$ in tumor tissue indicates that the binding and concomitant cellular uptake of extravasated TF-PEG liposomes occurred by TF receptor and receptor-mediated endocytosis, with the concentration of ${ }^{10} \mathrm{~B}$ in hepatocytes eventually decreasing, resulting in a tumor/normal tissue ratio of 2.0 at $48 \mathrm{~h}$ after liposomal injection.

Morphological and pathological analyses after BNCT. In order to examine the tumor growth-suppressing effects of BNCT, the VX-2 rabbit hepatic cancer model was subjected under general anesthesia to thermal neutron irradiation $48 \mathrm{~h}$ after the intraarterial injection of ${ }^{10} \mathrm{BSH}-\mathrm{TF}-\mathrm{PEG}-\mathrm{DSBL}$ liposomes at Kyoto University Institute for Integrated Radiation and Nuclear Science. The fluence of thermal neutrons was $2 \times 10^{12} \mathrm{n} / \mathrm{cm}^{-2}$ on the surface of the beam port, and details of the physical dose from each neutron energy range, including measurement results on the rear side, are shown in Table I. Rabbits were observed for 2 weeks, sacrificed, and liver tumors and the intraabdominal state were then examined. After BNCT, the suppression of tumor growth was noted with thermal neutron irradiation after the intra-arterial injection of ${ }^{10} \mathrm{BSH}-\mathrm{TF}-\mathrm{PEG}-$ DSBL liposomes, with smaller tumor sizes in the group treated with these liposomes than in the untreated group and the group treated only with thermal neutron irradiation (Figure 6; Table II). Many tumor nodules were detected in the liver, abdominal cavity, and peritoneum in the control group. Hematoxylin and
Table I. Irradiation mode at the Kyoto University Institute for Integrated Radiation and Nuclear Science for boron neutron capture therapy for the hepatic cancer model.

\begin{tabular}{lcc}
\hline Position & $\begin{array}{c}\text { Thermal neutron } \\
\text { fluence }\left(\mathrm{cm}^{-2}\right)\end{array}$ & $\begin{array}{c}\text { Epithermal neutron } \\
\text { fluence }\left(\mathrm{cm}^{-2}\right)\end{array}$ \\
\hline Surface & $2.0 \times 10^{12}$ & $8.9 \times 10^{11}$ \\
Rear side & $1.6 \times 10^{12}$ & $2.8 \times 10^{11}$ \\
\hline
\end{tabular}

Irradiation mode: Thermal neutron mode: OO-0000-F. 1 MW: 45 min. Cd ratio: $\sim 9.4$.

Table II. Tumor growth suppression by boron neutron capture therapy (BNCT) after an intra-arterial injection of ${ }^{10} \mathrm{~B}$-borono-dodecaborateentrapped transferrin-conjugated distearoyl-boron lipid-coated $\left({ }^{10} \mathrm{BSH}\right.$ TF-PEG-DSBL) liposomes into the VX-2 hepatic tumor model. VX-2 cells were inoculated into the left lobe of the liver of female New Zealand White rabbits. Two weeks after the inoculation, tumor-bearing rabbits were irradiated with thermal neutrons (fluence: $2 \times 10^{12} \mathrm{n} / \mathrm{cm}^{-2}$ ) $48 \mathrm{~h}$ after intra-arterial injection of ${ }^{10} B S H-T F-P E G-D S B L$ liposomes. After irradiation, the effects of BNCT were evaluated based on the tumor volume after 14 days (calculated as $1 / 2 \times$ length $\times$ width 2 ). Values are the means \pm standard deviation.

\begin{tabular}{lcc}
\hline Treatment & $\begin{array}{c}\text { Number of } \\
\text { rabbits }\end{array}$ & $\begin{array}{c}\text { Tumor size } \\
\left(\mathrm{mm}^{3}\right)\end{array}$ \\
\hline 10BSH TF-PEG-DSBL liposomes & 4 & $452.0 \pm 280.5$ \\
Thermal neutrons only & 2 & $1,474.3 \pm 37.8$ \\
Untreated & 1 & $2,232.6$ \\
\hline
\end{tabular}

eosin staining results shown in Figure 5 indicate the effectiveness of cancer cell killing by BNCT. Electron microscopic findings revealed apoptotic bodies and nuclear degradation in cancer cells (Figure 7).

\section{Discussion}

PEG liposomes have a long circulation time and biodistribution patterns and pharmacokinetics that enhance their systemic therapeutic effects. The PEG liposome formulation prevents rapid uptake by the reticuloendothelial system and, thus, liposomes remain in the circulation for long periods. 'Stealth' liposomes in tumors combine slower plasma clearance and higher vascular permeability compared with conventional liposomes, and form depots of drugs in the perivascular space after extravasation which are available to neighboring cells within tumors for a few days $(19,20)$. Ishida et $\mathrm{al}$. previously reported that PEG liposomes with an average diameter of 100-200 $\mathrm{nm}$ had the longest circulation time and the greatest accumulation in solid tumors in vivo (20). Maruyama et al. developed TF-binding PEG liposomes 
A

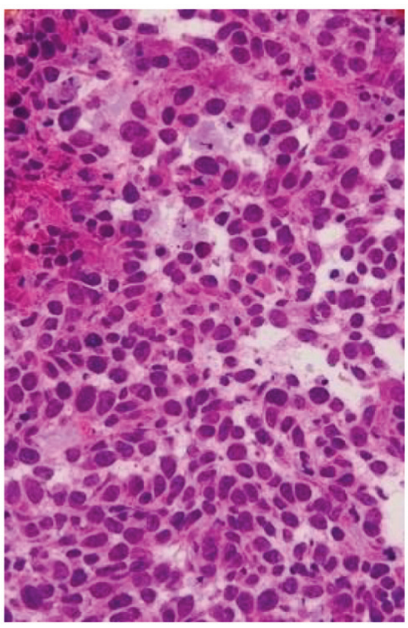

B
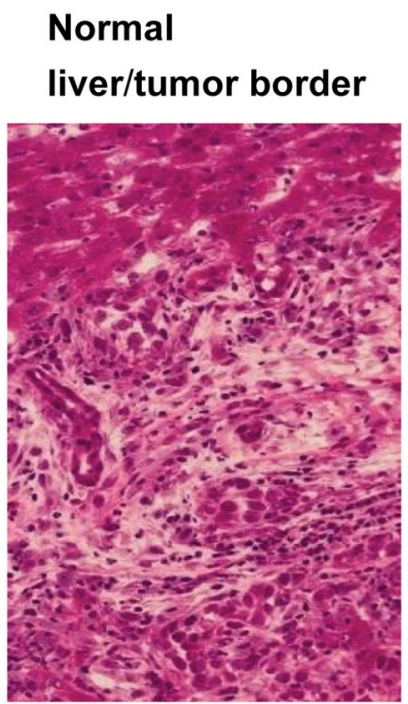

C

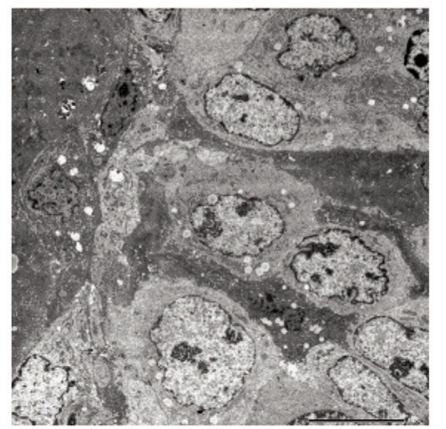

Normal liver (hepatic vein site)

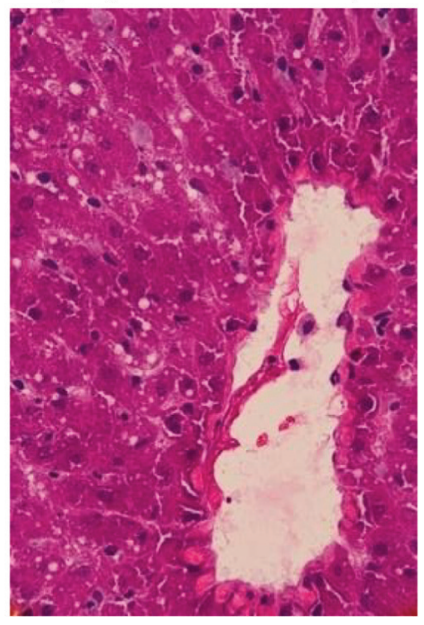

Normal liver (hepatic vein site)

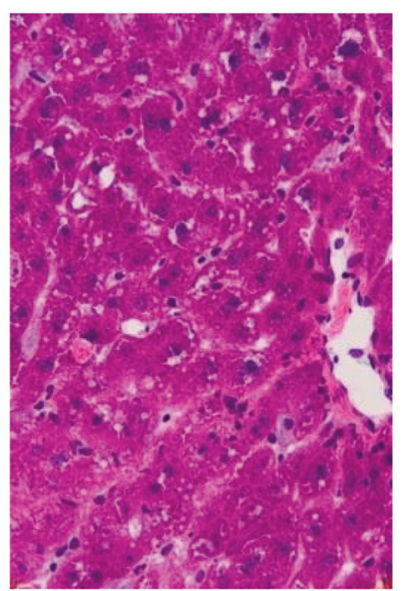

DSBL

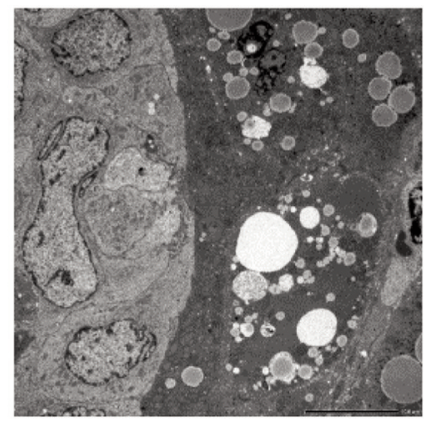

\section{Normal liver/tumor border}

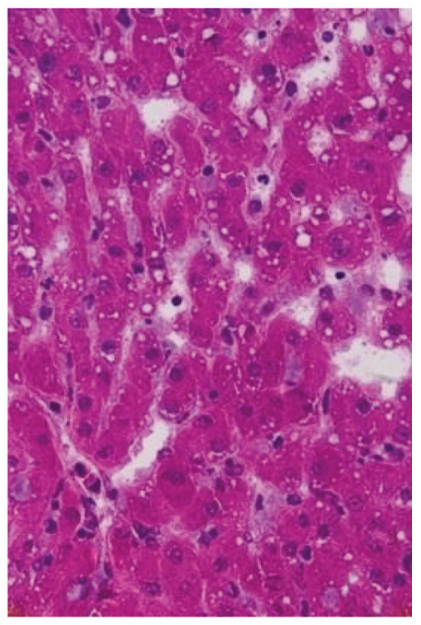

\section{Normal liver/tumor border}

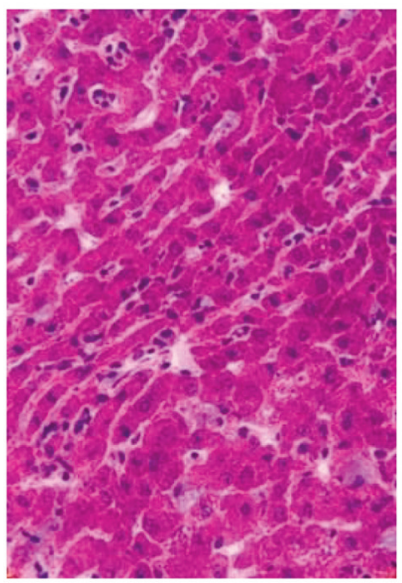

Control

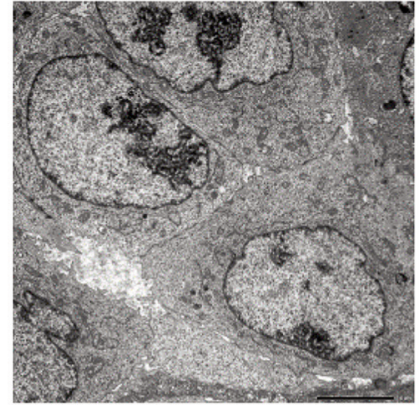

Figure 4. Pathological and histological examinations. No damage was observed in normal liver tissue under light (original magnification, $\times 200$ ) and electron microscopy (original magnification, $\times 600$ ) after intra-hepatic arterial injection of $10_{B}$-borono-dodecaborate-entrapped polyethyleneglycol distearoyl boron lipid-coated $\left({ }^{10} B S H-P E G-D S B L\right)$ liposomes. A: Fat droplets were detected at the boundary of the tumor and normal hepatic tissue $24 \mathrm{~h}$ after administration. Degeneration and hyalinization were not observed in hepatocytes. B: Fat droplets were only noted in the liver vein surrounding the hepatic lobulus after $48 \mathrm{~h}$. This phenomenon may have been due to the drainage of lipids constructed of liposomes from the liver. C: More fatty vesicles were detected in VX-2 tumor tissues 24 h after the intra-arterial injection of ${ }^{10} B S H-P E G-D S B L$ liposomes than in non-treated control groups by electron microscopy. 


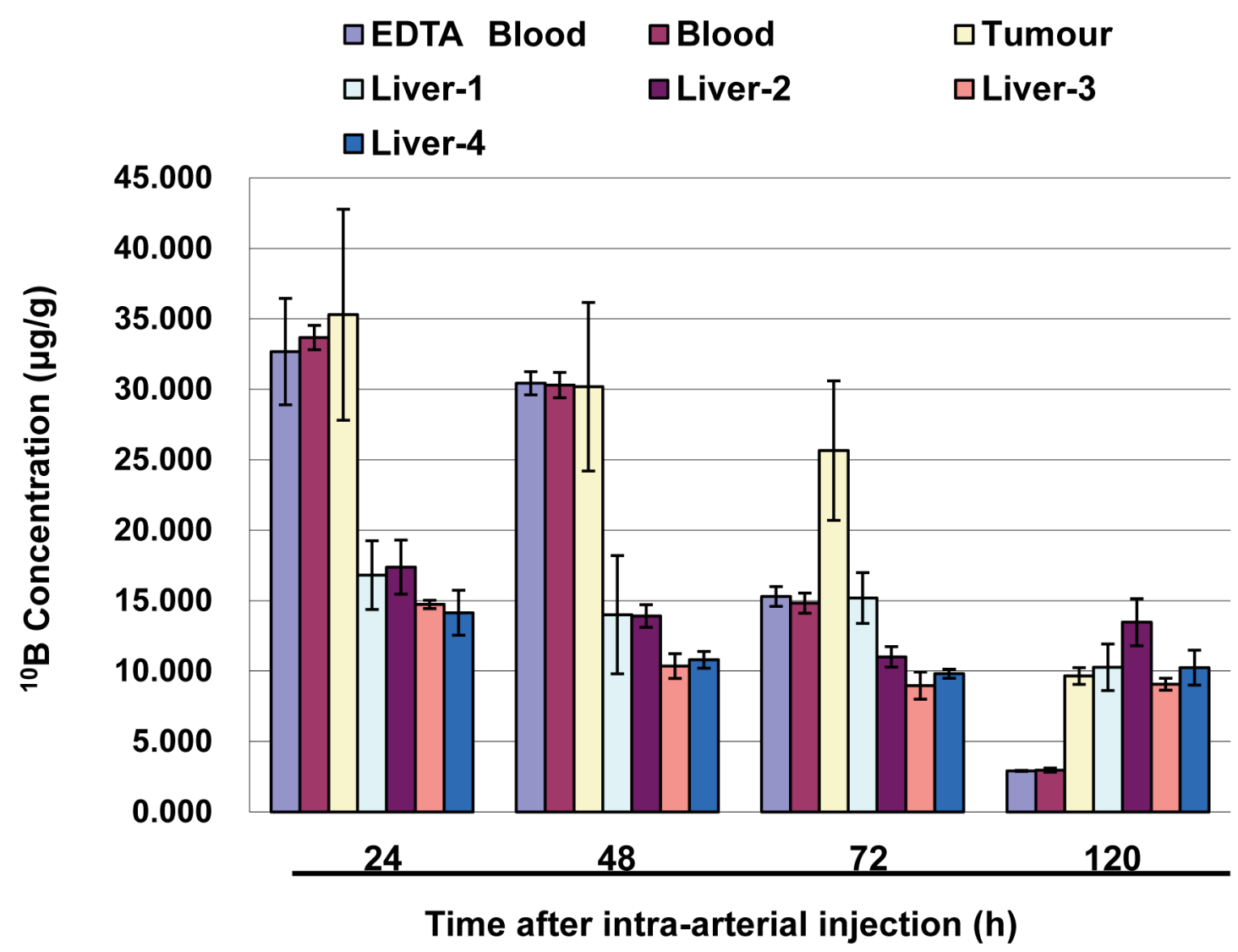

Figure 5. Boron concentrations in tumors and normal hepatic tissue in the VX-2 rabbit hepatic cancer model after intra-hepatic arterial injection of ${ }^{10} \mathrm{~B}$-borono-dodecaborate -entrapped transferrin-conjugated polyethyleneglycol distearoyl-boron lipid liposomes. Liver-1: Normal liver near tumor in left lobe of liver; Liver-2: normal liver edge in left lobe of liver; Liver-3: normal liver central area in right lobe of liver; Liver-4: normal liver edge in right lobe of liver.

as an intracellular drug delivery system by receptor-mediated endocytosis (25).

The presence of a ligand facilitates the entry of ${ }^{10} \mathrm{~B}$ containing compounds into cells through receptor-mediated endocytosis (11). We showed the suppression of tumor growth in a human pancreatic cancer model by BNCT after repeated intravenous injections of ${ }^{10} \mathrm{BSH}$-entrapped $\mathrm{PEG}$ liposomes (18). Furthermore, ${ }^{10} \mathrm{BSH}-\mathrm{TF}-\mathrm{PEG}$ liposomes achieved superior tumor growth suppression by BNCT (19), and using neutron capture autoradiography, we demonstrated that ${ }^{10} \mathrm{~B}$ atoms more selectively accumulated in tumors using ${ }^{10} \mathrm{BSH}$-entrapped TF-PEG liposomes than conventional liposomes (26).

Nakamura et al. reported several boron lipids constructed of liposomes, which increased the uptake of boron-10 atoms in cancer cells, and termed these liposomal Boron Delivery Systems (27). ${ }^{10} \mathrm{BSH}-\mathrm{DSBL}-\mathrm{PEG}$ liposomes have been developed, and their significant antitumor effects were observed in mice injected with these liposomes $\left(15 \mathrm{mg}{ }^{10} \mathrm{~B} / \mathrm{kg}\right)$ after thermal neutron irradiation (22). Furthermore, liposomes composed of the closo-dodecaborate lipids DSBL and dipalmitoyl boron lipid exhibited strong cytotoxicity with thermal neutron irradiation, and these lipid liposomes were taken up into the cytoplasm by endocytosis without degradation (21). TF-loaded nido-carborane liposomes also achieved a higher survival rate with BNCT in tumor-bearing mice (28).

Boron compounds are currently being developed (29-35). Previous studies showed that tumor uptake after the administration of a sulfhydryl borane dimer $\left(\mathrm{Na}_{4} \mathrm{~B}_{24} \mathrm{H}_{22} \mathrm{~S}_{2}\right)$ was approximately two-fold that after the administration of equal amounts of boron as a monomer $(36,37)$. Feakes et al. encapsulated the apical-equatorial isomer of polyhedral borane $\left[\mathrm{B}_{20} \mathrm{H}_{17} \mathrm{NH}_{3}\right]$-ion in liposomes prepared with 5\% PEG-2000distearoyl phosphatidyl-ethanolamine and found that the circulation time of these liposomes was prolonged, resulting in the continued accumulation of boron in tumors (38-41).

Cemazar et al. performed an electric pulse technique to enhance the accumulation of ${ }^{10} \mathrm{~B}$ into cancer cells after the 


\section{BNCT}
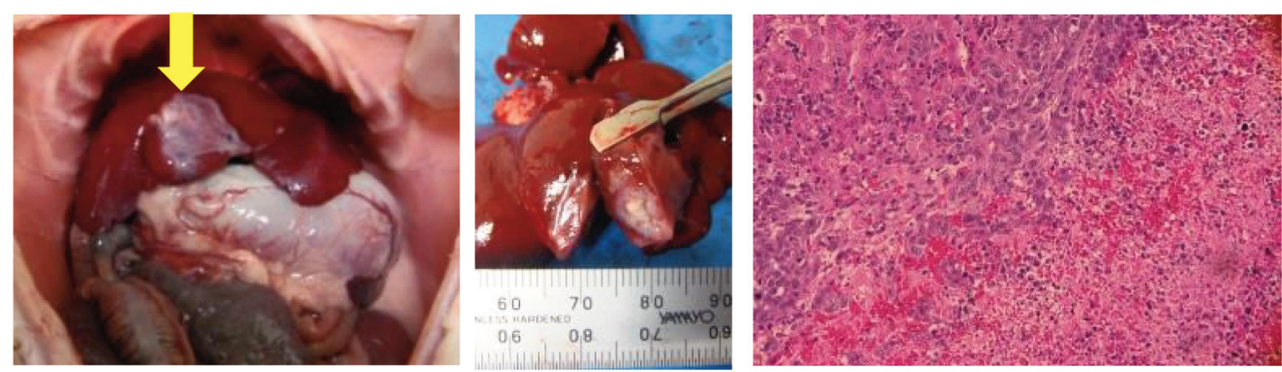

Thermal neutron therapy only
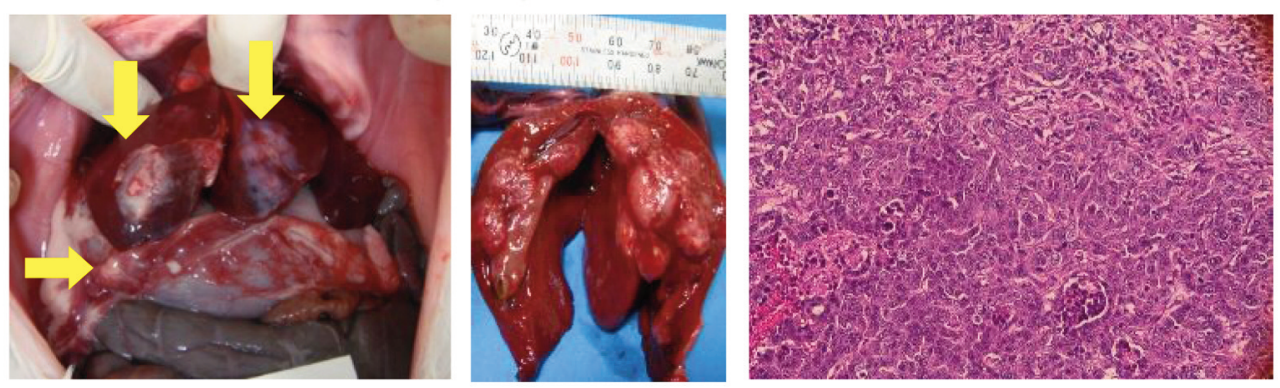

Untreated control
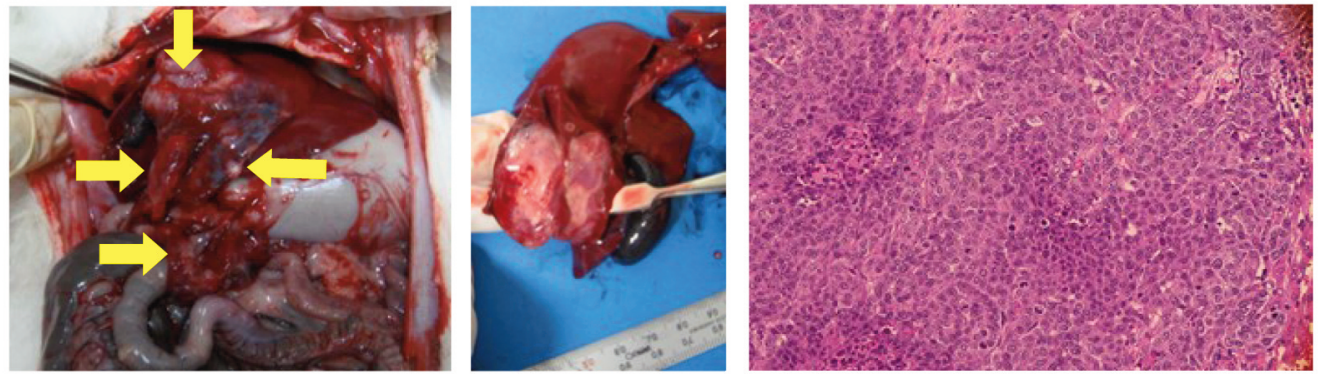

Figure 6. Tumor growth suppression by boron neutron capture therapy (BNCT). Morphological and pathological findings of VX-2 tumors after BNCT with intra-arterial injection of ${ }^{10} B$-borono-dodecaborate-entrapped transferrin-conjugated polyethyleneglycol-distearoylboron lipid-coated liposomes.
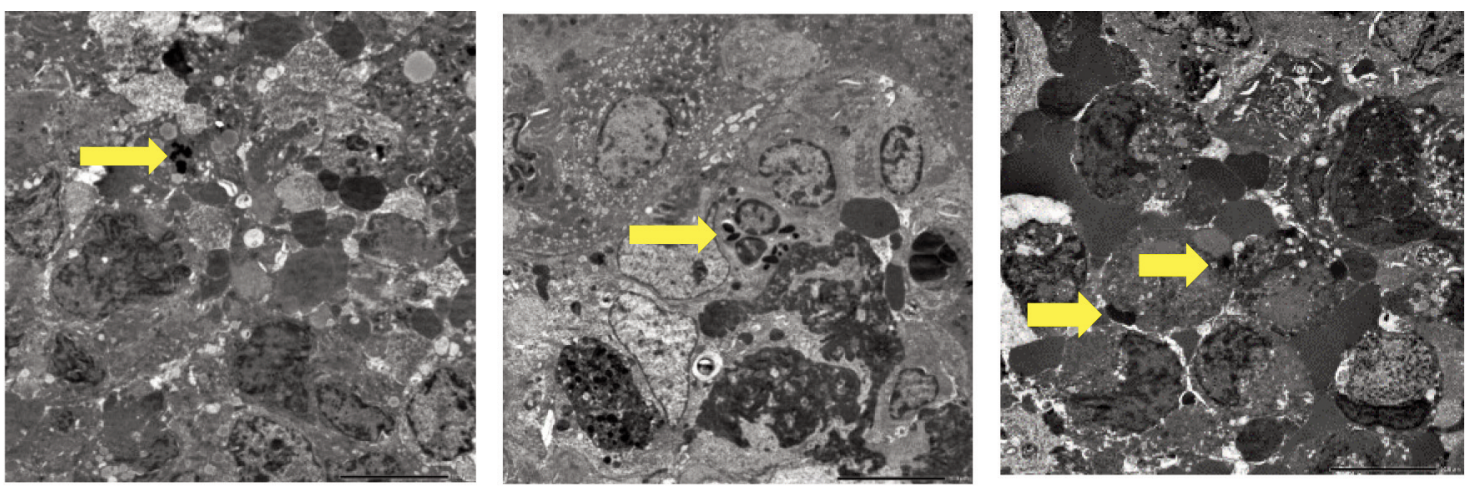

Figure 7. Electron microscopy findings $(\times 600)$ of tumors after boron neutron capture therapy using intra-hepatic arterial injection of ${ }^{10} B$-boronododecaborate-entrapped transferrin-conjugated polyethyleneglycol-distearoylboron lipid-coated liposomes. Nuclear deformation and apoptotic bodies were detected in tumor cells. 
intravenous injection of ${ }^{10} \mathrm{~B}$-borono-phenylalanine (42). BNCT with an intravenous injection of TF-PEG liposomes with a high content of ${ }^{10} \mathrm{BSH}$ has the ability to destroy malignant cells at the edge of the tumor mass, which is a hypervascular area. Experiments with these new ${ }^{10} \mathrm{~B}$ delivery systems that combine ${ }^{10} \mathrm{BSH}-\mathrm{TF}-\mathrm{PEG}$ liposomes using the electric pulse technique to enhance the uptake of ${ }^{10} \mathrm{~B}$ will hopefully soon proceed to clinical BNCT trials.

The development of boron lipids for the construction of liposomes is very important because liposomes with boron atoms will increase the concentration of boron in cancer cells by liposomal endocytosis $(21,22,28)$. The density of boron was previously shown to be higher in tumors than in normal hepatic tissue following modifications to the surface of PEG liposomes with TF, and tumor growth-suppressing effects were confirmed by thermal neutron irradiation $(19,21,22$, $28,31)$. Intelligent targeting prevents accumulation in normal hepatic tissue and tumor selectivity in targeting is expected. In our study, the intra-arterial injection of ${ }^{10} \mathrm{BSH}$-TF-PEGDSBL liposomes increased tumor retention of ${ }^{10} \mathrm{~B}$ atoms and also suppressed tumor growth in vivo upon thermal neutron irradiation. Pathological damage was not observed in normal hepatocytes after BNCT. The present results demonstrated the potential of ${ }^{10} \mathrm{BSH}$ TF PEG-DSBL Lip as a novel intraarterial boron carrier in BNCT for cancer.

Suzuki et al. reported preclinical studies and the treatment of patients with HCC by $\operatorname{BNCT}(43,44)$. We also demonstrated that VX-2 tumor growth was suppressed by BNCT after an intra-hepatic arterial injection of ${ }^{10} \mathrm{BSH}-$ entrapped WOW emulsion, and performed a clinical study on BNCT using ${ }^{10} \mathrm{BSH}$-entrapped WOW emulsion for patients with $\mathrm{HCC}(45,46)$.

There were limitations to intra-arterial injection of drugs in these experiments as the proper hepatic artery of the rabbit is very thin, and it is very difficult to apply an injectional catheter to branches of hepatic arteries super-selectively. We hope to develop the boron-entrapped delivery systems for selective accumulation in tumors using this rabbit model, then proceed to a pilot clinical study of BNCT in the near future.

\section{Conclusion}

We prepared ${ }^{10} \mathrm{BSH}$-entrapped TF-PEG liposomes consisting of boron lipids (DSBL) as boron delivery systems in BNCT. The results demonstrated that ${ }^{10} \mathrm{BSH}-\mathrm{TF}-\mathrm{PEG}-\mathrm{DSBL}$ liposomes deliver and facilitate the retention of boron atoms in cancer cells of tumor tissues in a rabbit hepatic tumor model. Tumor growth was suppressed by thermal neutron irradiation after an intra-arterial injection of ${ }^{10} \mathrm{BSH}-\mathrm{TF}-\mathrm{PEG}-$ DSBL liposomes without damage to normal cells. These results demonstrate the potential of ${ }^{10} \mathrm{BSH}-\mathrm{TF}-\mathrm{PEG}-\mathrm{DSBL}$ liposomes as a novel boron delivery carrier in BNCT for cancer using intra-arterial techniques. We intend to proceed to preclinical safety and clinical studies on patients with HCC using ${ }^{10} \mathrm{BSH}-\mathrm{TF}-\mathrm{PEG}-\mathrm{DSBL}$ liposomes in the near future.

\section{Conflicts of Interest}

None declared.

\section{Authors' Contributions}

Conceived and designed the experiments; HY, HN, MS, YS, HT, SM, KO, and HT. Performed the experiments; HY, MY, YM, AS, RM, YM, MS, YS, HT, SM, and KO. Analyzed and interpreted the data; HY, YM, AS, HN, MS, YS, ND, YN, YF, and HT. Contributed reagents, materials, analysis tools or data; HY, YM, AS, HN, MS, YS, TS, MN, HY, MO, JN, and HT. Wrote the article; HY, ND, HN, MS, and HT.

\section{Acknowledgements}

This work was supported in part by Grants-in-Aid from the Ministry of Education, Science and Culture of Japan (No. 11691202 and No. 11557092 to Hironobu Yanagie), and a Grant-in-Aid from the Ministry of Health, Labour and Welfare of Japan (No. 2008-Nano004 to Hiroyuki Nakamura). We express our appreciation to Mrs. Yuriko Sakurai and Mrs. Kikue Mouri for their preparation of pathological samples.

\section{References}

1 Chen Z, Xie H, Hu M, Huang T, Hu Y, Sang N and Zhao Y: Recent progress in treatment of hepatocellular carcinoma. Am J Cancer Res 10(9): 2993-3036, 2020. PMID: 33042631.

2 Yang JD, Hainaut P, Gores GJ, Amadou A, Plymoth A and Roberts LR: A global view of hepatocellular carcinoma: trends, risk, prevention and management. Nat Rev Gastroenterol Hepatol 16(10): 589-604, 2019. PMID: 31439937. DOI: 10.1038/s41575-019-0186-y

3 Kanematsu T, Inokuchi K, Sugimachi K, Furuta T, Sonoda T, Tamura S and Hasuo K: Selective effects of Lipiodolized antitumor agents. J Surg Oncol 25(3): 218-226, 1984. PMID: 6199624. DOI: $10.1002 /$ jso.2930250317

4 Higashi S, Shimizu M, Nakashima T, Iwata K, Uchiyama F, Tateno S, Tamura S and Setoguchi T: Arterial-injection chemotherapy for hepatocellular carcinoma using monodispersed poppy-seed oil microdroplets containing fine aqueous vesicles of epirubicin. Initial medical application of a membrane-emulsification technique. Cancer 75(6): 1245-1254, 1995. PMID: 7882276. DOI: 10.1002/ 1097-0142(19950315)75:6<1245::aid-cncr2820750606>3.0.co;2-u

5 Higashi S, Tabata N, Kondo KH, Maeda Y, Shimizu M, Nakashima T and Setoguchi T: Size of lipid microdroplets effects results of hepatic arterial chemotherapy with an anticancer agent in water-in-oil-in-water emulsion to hepatocellular carcinoma. J Pharmacol Exp Ther 289(2): 816819, 1999. PMID: 10215657.

6 Ikushima I, Higashi S, Ishii A, Seguchi K, Iryo Y and Yamashita Y: Ultraselective transcatheter infusion of epirubicin in waterin-oil-in-water emulsion for small hepatocellular carcinoma. $\mathrm{Br}$ 
J Radiol 85(1017): e584-e589, 2012. PMID: 22422389. DOI: $10.1259 / \mathrm{bjr} / 16376960$

7 Hatanaka H and Nakagawa Y: Clinical results of long-surviving brain tumor patients who underwent boron neutron capture therapy. Int J Radiat Oncol Biol Phys 28(5): 1061-1066, 1994. PMID: 8175390. DOI: 10.1016/0360-3016(94)90479-0

8 Mishima Y, Honda C, Ichihashi M, Obara H, Hiratsuka J, Fukuda H, Karashima H, Kobayashi T, Kanda K and Yoshino K: Treatment of malignant melanoma by single thermal neutron capture therapy with melanoma-seeking 10B-compound. Lancet 2(8659): 388-389, 1989. PMID: 2569577. DOI: 10.1016/s01406736(89)90567-9

9 Ono K, Ueda S, Oda Y, Nakagawa Y, Miyatake S, Takagaki M, Osawa $\mathrm{M}$ and Kobayashi T: Boron neutron-capture therapy for malignant glioma at Kyoto University reactor. In: Advances in Neutron-Capture Therapy, Volume I, Medicine and Physics. Larsson B, Crawford J and Weinreich R (eds). Amsterdam, Elsevier Science, pp. 39-45, 1997.

10 Yanagië H, Ogata A, Sugiyama H, Eriguchi M, Takamoto S and Takahashi H: Application of drug delivery system to boron neutron capture therapy for cancer. Expert Opin Drug Deliv 5(4): 427-443, 2008. PMID: 18426384. DOI: 10.1517/17425247.5.4.427

11 Barth RF, Mi P and Yang W: Boron delivery agents for neutron capture therapy of cancer. Cancer Commun (Lond) 38(1): 35, 2018. PMID: 29914561. DOI: 10.1186/s40880-018-0299-7

12 Mi P: Stimuli-responsive nanocarriers for drug delivery, tumor imaging, therapy and theranostics. Theranostics 10(10): 45574588, 2020. PMID: 32292515. DOI: 10.7150/thno.38069

13 Luderer MJ, Muz B, Alhallak K, Sun J, Wasden K, Guenthner N, de la Puente P, Federico C and Azab AK: Thermal sensitive liposomes improve delivery of boronated agents for boron neutron capture therapy. Pharm Res 36(10): 144, 2019. PMID: 31392417. DOI: $10.1007 / \mathrm{s} 11095-019-2670-\mathrm{Z}$

14 Nomoto T, Inoue Y, Yao Y, Suzuki M, Kanamori K, Takemoto H, Matsui M, Tomoda K and Nishiyama N: Poly(vinyl alcohol) boosting therapeutic potential of $p$-boronophenylalanine in neutron capture therapy by modulating metabolism. Sci Adv 6(4): eaaz1722, 2020. PMID: 32010792. DOI: 10.1126/sciadv. aaz1722

15 Yoneoka S, Nakagawa Y, Uto K, Sakura K, Tsukahara T and Ebara M: Boron-incorporating hemagglutinating virus of Japan envelope (HVJ-E) nanomaterial in boron neutron capture therapy. Sci Technol Adv Mater 20(1): 291-304, 2019. PMID: 30956733. DOI: 10.1080/14686996.2019.1586051

16 Yanagië H, Tomita T, Kobayashi H, Fujii Y, Takahashi T, Hasumi K, Nariuchi H and Sekiguchi M: Application of boronated antiCEA immunoliposome to tumour cell growth inhibition in in vitro boron neutron capture therapy model. Br J Cancer 63(4): 522-526, 1991. PMID: 2021537. DOI: 10.1038/bjc.1991.124

17 Yanagië H, Tomita T, Kobayashi H, Fujii Y, Nonaka Y, Saegusa Y, Hasumi K, Eriguchi M, Kobayashi T and Ono K: Inhibition of human pancreatic cancer growth in nude mice by boron neutron capture therapy. Br J Cancer 75(5): 660-665, 1997. PMID: 9043021. DOI: 10.1038/bjc.1997.118

18 Yanagie H, Maruyama K, Takizawa T, Ishida O, Ogura K, Matsumoto T, Sakurai Y, Kobayashi T, Shinohara A, Rant J, Skvarc J, Ilic R, Kuhne G, Chiba M, Furuya Y, Sugiyama H, Hisa T, Ono K, Kobayashi H and Eriguchi M: Application of boron-entrapped stealth liposomes to inhibition of growth of tumour cells in the in vivo boron neutron-capture therapy model.
Biomed Pharmacother 60(1): 43-50, 2006. PMID: 16260113. DOI: $10.1016 /$ j.biopha.2005.05.011

19 Maruyama K, Ishida O, Kasaoka S, Takizawa T, Utoguchi N, Shinohara A, Chiba M, Kobayashi H, Eriguchi M and Yanagie H: Intracellular targeting of sodium mercaptoundecahydro-dodecaborate (BSH) to solid tumors by transferrin-PEG liposomes, for boron neutron-capture therapy (BNCT). J Control Release 98(2): 195-207, 2004. PMID: 15262412. DOI: 10.1016/j.jconrel.2004.04.018

20 Ishida O, Maruyama K, Tanahashi H, Iwatsuru M, Sasaki K, Eriguchi $\mathrm{M}$ and Yanagie H: Liposomes bearing polyethyleneglycolcoupled transferrin with intracellular targeting property to the solid tumors in vivo. Pharm Res 18(7): 1042-1048, 2001. PMID: 11496943. DOI: 10.1023/a:1010960900254

21 Ueno M, Ban HS, Nakai K, Inomata R, Kaneda Y, Matsumura A and Nakamura H: Dodecaborate lipid liposomes as new vehicles for boron delivery system of neutron capture therapy. Bioorg Med Chem 18(9): 3059-3065, 2010. PMID: 20371186. DOI: $10.1016 / j . b m c .2010 .03 .050$

22 Koganei H, Ueno M, Tachikawa S, Tasaki L, Ban HS, Suzuki M, Shiraishi K, Kawano K, Yokoyama M, Maitani Y, Ono K and Nakamura H: Development of high boron content liposomes and their promising antitumor effect for neutron capture therapy of cancers. Bioconjug Chem 24(1): 124-132, 2013. PMID: 23214414. DOI: $10.1021 / \mathrm{bc} 300527 \mathrm{n}$

23 Burgener FA: Peripheral hepatic artery embolization in rabbits with VX2 carcinomas of the liver. Cancer 46(1): 56-63, 1980. PMID: 7388767. DOI: 10.1002/1097-0142(19800701)46: 1<56::aid-cncr2820460113>3.0.co;2-c

24 Shinohara A, Chiba M and Inaba Y: Determination of selenium concentrations in human blood plasma by microwave-induced plasma mass spectrometry. Analytical Sciences 14(4): 713-717, 2021. DOI: $10.2116 /$ analsci.14.713

25 Maruyama K, Takizawa T, Yuda T, Kennel SJ, Huang L and Iwatsuru M: Targetability of novel immunoliposomes modified with amphipathic poly(ethylene glycol)s conjugated at their distal terminals to monoclonal antibodies. Biochim Biophys Acta 1234(1): 74-80, 1995. PMID: 7880861. DOI: 10.1016/00052736(94)00263-o

26 Yanagië H, Ogura K, Takagi K, Maruyama K, Matsumoto T, Sakurai Y, Skvarc J, Illic R, Kuhne G, Hisa T, Yoshizaki I, Kono K, Furuya Y, Sugiyama H, Kobayashi H, Ono K, Nakagawa K and Eriguchi M: Accumulation of boron compounds to tumor with polyethylene-glycol binding liposome by using neutron capture autoradiography. Appl Radiat Isot 61(4): 639-646, 2004. PMID: 15246411. DOI: 10.1016/j.apradiso.2004.03.109

27 Nakamura H: Boron lipid-based liposomal boron delivery system for neutron capture therapy: recent development and future perspective. Future Med Chem 5(6): 715-730, 2013. PMID: 23617433. DOI: $10.4155 / \mathrm{fmc} .13 .48$

28 Miyajima Y, Nakamura H, Kuwata Y, Lee JD, Masunaga S, Ono $\mathrm{K}$ and Maruyama K: Transferrin-loaded nido-carborane liposomes: tumor-targeting boron delivery system for neutron capture therapy. Bioconjug Chem 17(5): 1314-1320, 2006. PMID: 16984142. DOI: 10.1021/bc060064k

29 Nakase I, Katayama M, Hattori Y, Ishimura M, Inaura S, Fujiwara D, Takatani-Nakase T, Fujii I, Futaki S and Kirihata M: Intracellular target delivery of cell-penetrating peptideconjugated dodecaborate for boron neutron capture therapy (BNCT). Chem Commun (Camb) 55(93): 13955-13958, 2019. PMID: 31617510. DOI: 10.1039/c9cc03924d 
30 Michiue H, Sakurai Y, Kondo N, Kitamatsu M, Bin F, Nakajima K, Hirota Y, Kawabata S, Nishiki T, Ohmori I, Tomizawa K, Miyatake S, Ono K and Matsui $\mathrm{H}$ : The acceleration of boron neutron capture therapy using multi-linked mercaptoundecahydrododecaborate (BSH) fused cell-penetrating peptide. Biomaterials 35(10): 3396-3405, 2014. PMID: 24452095. DOI: 10.1016/j.biomaterials.2013.12.055

31 Masunaga S, Kasaoka S, Maruyama K, Nigg D, Sakurai Y, Nagata K, Suzuki M, Kinashi Y, Maruhashi A and Ono K: The potential of transferrin-pendant-type polyethyleneglycol liposomes encapsulating decahydrodecaborate-(10)B (GB-10) as (10)Bcarriers for boron neutron capture therapy. Int J Radiat Oncol Biol Phys 66(5): 1515-1522, 2006. PMID: 17126210. DOI: 10.1016/j.ijrobp.2006.08.028

32 Takeuchi K, Hattori Y, Kawabata S, Futamura G, Hiramatsu R, Wanibuchi M, Tanaka H, Masunaga SI, Ono K, Miyatake SI and Kirihata M: Synthesis and evaluation of dodecaboranethiol containing kojic acid (KA-BSH) as a novel agent for boron neutron capture therapy. Cells 9(6): 1551, 2020. PMID: 32630612. DOI: 10.3390/cells9061551

33 Maitz CA, Khan AA, Kueffer PJ, Brockman JD, Dixson J, Jalisatgi SS, Nigg DW, Everett TA and Hawthorne MF: Validation and comparison of the therapeutic efficacy of boron neutron capture therapy mediated by boron-rich liposomes in multiple murine tumor models. Transl Oncol 10(4): 686-692, 2017. PMID: 28683435. DOI: 10.1016/j.tranon.2017.05.003

34 Nakase I, Aoki A, Sakai Y, Hirase S, Ishimura M, TakataniNakase T, Hattori Y and Kirihata M: Antibody-based receptor targeting using an Fc-binding peptide-dodecaborate conjugate and macropinocytosis induction for boron neutron capture therapy. ACS Omega 5(36): 22731-22738, 2020. PMID: 32954120. DOI: 10.1021/acsomega.0c01377

35 Nakagawa F, Kawashima H, Morita T and Nakamura H: Watersoluble closo-docecaborate-containing pteroyl derivatives targeting folate receptor-positive tumors for boron neutron capture therapy. Cells 9(7): 1615, 2020. PMID: 32635272. DOI: 10.3390/cells9071615

36 Slatkin D, Micca P, Forman A, Gabel D, Wielopolski L and Fairchild R: Boron uptake in melanoma, cerebrum and blood from Na2B12H11SH and Na4B24H22S2 administered to mice. Biochem Pharmacol 35(10): 1771-1776, 1986. PMID: 3707608. DOI: 10.1016/0006-2952(86)90342-4

37 Elhanati G, Salomon Y and Bendel P: Significant differences in the retention of the borocaptate monomer $(\mathrm{BSH})$ and dimer (BSSB) in malignant cells. Cancer Lett 172(2): 127-132, 2001. PMID: 11566486. DOI: 10.1016/s0304-3835(01)00649-8

38 Feakes DA, Shelly K, Knobler CB and Hawthorne MF: $\mathrm{Na3}[\mathrm{B} 20 \mathrm{H} 17 \mathrm{NH} 3]$ : synthesis and liposomal delivery to murine tumors. Proc Natl Acad Sci USA 91(8): 3029-3033, 1994. PMID: 8159700. DOI: 10.1073/pnas.91.8.3029

39 Feakes DA, Shelly K and Hawthorne MF: Selective boron delivery to murine tumors by lipophilic species incorporated in the membranes of unilamellar liposomes. Proc Natl Acad Sci USA 92(5): 1367-1370, 1995. PMID: 7877984. DOI: 10.1073/ pnas.92.5.1367
40 Feakes DA, Waller RC, Hathaway DK and Morton VS: Synthesis and in vivo murine evaluation of $\mathrm{Na} 4$ [1-(1'-B10H9)6-SHB10H8] as a potential agent for boron neutron capture therapy. Proc Natl Acad Sci USA 96(11): 6406-6410, 1999. PMID: 10339600. DOI: 10.1073/pnas.96.11.6406

41 Shelly K, Feakes DA, Hawthorne MF, Schmidt PG, Krisch TA and Bauer WF: Model studies directed toward the boron neutron-capture therapy of cancer: boron delivery to murine tumors with liposomes. Proc Natl Acad Sci USA 89(19): 90399043, 1992. PMID: 1409600. DOI: 10.1073/pnas.89.19.9039

42 Cemazar M, Skrk J, Mitrovic B and Sersa G: Changed delivery of boron to tumours using electroporation for boron neutron capture therapy with BSH. Br J Radiol 73(866): 195-200, 2000. PMID: 10884734. DOI: 10.1259/bjr.73.866.10884734

43 Suzuki M, Sakurai Y, Hagiwara S, Masunaga S, Kinashi Y, Nagata K, Maruhashi A, Kudo M and Ono K: First attempt of boron neutron capture therapy (BNCT) for hepatocellular carcinoma. Jpn J Clin Oncol 37(5): 376-381, 2007. PMID: 17578894. DOI: $10.1093 / \mathrm{jjco} / \mathrm{hym} 039$

44 Suzuki M, Masunaga S, Kinashi Y, Nagata K, Sakurai Y, Nakamatsu K, Nishimura Y, Maruhashi A and Ono K: Intraarterial administration of sodium borocaptate (BSH)/lipiodol emulsion delivers B-10 to liver tumors highly selectively for boron neutron capture therapy: experimental studies in the rat liver model. Int J Radiat Oncol Biol Phys 59(1): 260-266, 2004. PMID: 15093923. DOI: 10.1016/j.jirobp.2003.12.018

45 Yanagie H, Dewi N, Higashi S, Ikushima I, Seguchi K, Mizumachi R, Murata Y, Morishita Y, Shinohara A, Mikado S, Yasuda N, Fujihara M, Sakurai Y, Mouri K, Yanagawa M, Iizuka T, Suzuki M, Sakurai Y, Masunaga SI, Tanaka H, Matsukawa T, Yokoyama K, Fujino T, Ogura K, Nonaka Y, Sugiyama H, Kajiyama T, Yui S, Nishimura R, Ono K, Takamoto S, Nakajima J, Ono M, Eriguchi M, Hasumi K and Takahashi H: Selective boron delivery by intra-arterial injection of BSH-WOW emulsion in hepatic cancer model for neutron capture therapy. Br J Radiol 90(1074): 20170004, 2017. PMID: 28406315. DOI: 10.1259/bjr.20170004

46 Yanagie H, Higashi S, Seguchi K, Ikushima I, Fujihara M, Nonaka Y, Oyama K, Maruyama S, Hatae R, Suzuki M, Masunaga S, Kinashi T, Sakurai Y, Tanaka H, Kondo N, Narabayashi M, Kajiyama T, Maruhashi A, Ono K, Nakajima J, Ono M, Takahashi $\mathrm{H}$ and Eriguchi M: Pilot clinical study of boron neutron capture therapy for recurrent hepatic cancer involving the intra-arterial injection of a (10)BSH-containing WOW emulsion. Appl Radiat Isot 88: 32-37, 2014. PMID: 24559940. DOI: $10.1016 /$ j.apradiso.2014.01.014

Received July 2, 2021

Revised September 23, 2021 Accepted September 24, 2021 